\title{
Research on Fuzzy PID Control of Building Hydroelectric Speed Regulating System
}

\author{
Guanlu Yang $^{\mathrm{a}}$, Shuyang Wang ${ }^{\mathrm{b}}$, Zehong Huang ${ }^{\mathrm{c}}$ \\ College of Information Science and Engineering, Huaqiao University, Xiamen 361021, China \\ aglyang@hqu.edu.cn, b443949162@qq.com, c535830236@qq.com
}

Keywords: Building water energy, Fuzzy PID Controller, On-grid.

Abstract: Under the background of energy shortage and environmental pollution, the development and utilization of building water energy and resource utilization have actively responded to the construction of the national sponge city and are in line with the sustainable development strategy. It can not only solve the current situation of urban shortage of fresh water resources, but also alleviate the pressure of insufficient power supply in large cities. In this paper, the problem of grid connection of building hydropower system is studied. The fuzzy PID controller is used as the governor of the turbine, so that the output frequency of the hydroelectric generator can be stabilized at $50 \mathrm{~Hz}$ to meet the frequency conditions of the grid connection. Through theoretical research and use of Matlab The simulation is carried out to simulate the startup process and the load shedding process of the hydroelectric generator. The results show that the fuzzy PID controller designed in this paper can play a good role in speed regulation, and the energy generated by the building hydropower system can be combined. The use of the network laid the foundation.

\section{Introduction}

With the development of the social economy, the population is growing, the urbanization is developing faster and faster, and the buildings are rising. However, due to the shortage of water resources in China, it seriously restricts the development of cities [1]. The building hydropower system can not only fully collect and utilize fresh water resources, but also alleviate the pressure of water supply and power shortage in large cities, improve and protect the ecological environment of the city, and have positive significance for the construction of ecological civilization.

At present, building hydropower systems mainly include array distributed power generation systems and confluent centralized power generation systems [2]. Array distributed generation system theory is feasible, but the actual operation is more difficult, so this paper chooses the confluent centralized power generation system. The principle is to collect building water energy at high places, including rainwater and medium water. Then, it flows into the low-level turbine through the pressure pipeline to generate electricity, and the tail water of the turbine is collected and utilized twice. The rain is relatively clean, the cost is low, and the economic benefits are high. It can also reduce runoff pollution and urban floods.

\section{Design Plan}

The system uses the fuzzy PID control method to design the turbine's speed control system so that the frequency of the energy emitted by the turbine can be stabilized at $50 \mathrm{~Hz}$. Turbine speed and power generation system model shown in Figure 1. 


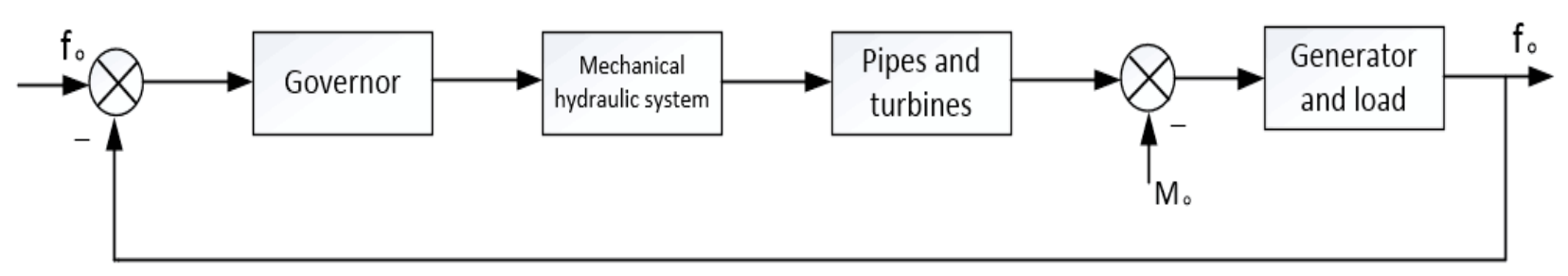

Figure 1 Turbine speed regulation and power generation system

The turbine speed control and power generation system is mainly composed of four parts: governor, mechanical hydraulic system, pipeline and turbine, generator and load[3]. The governor is a fuzzy PID controller. The mechanical hydraulic system represents the opening of the water valve of the storage device or the opening of the water inlet of the turbine in the building hydroelectric system.

The mechanical hydraulic system is the actuator of the governor. It represents the opening of the water valve or the opening of the water inlet of the turbine in the building hydroelectric system, and then controls the size of the flow of the turbine, thus controlling the output frequency of the hydraulic generator. Since the main relay time constant Ty is much larger than the auxiliary servo time constant, the auxiliary relay time constant can be ignored, so the transfer function of the mechanical hydraulic system is [4]:

$$
\mathrm{G}_{\mathrm{r}}(\mathrm{s})=\frac{1}{\mathrm{~T}_{\mathrm{y}} \mathrm{s}}
$$

The mathematical model for pipelines and turbines is[5]:

$$
G_{t}(s) \frac{e_{y}-\left(e_{h} e_{q y}-e_{y} e_{q h}\right) T_{w} s}{1+e_{q h} T_{w} s}
$$

Where ey is the transfer function of the turbine torque to the valve opening stroke, eh is the transfer function of the turbine torque to the head, eqy is the transfer function of the turbine flow to the valve opening stroke, eqh is the torque of the turbine to the head The transfer function, Tw is the flow inertia time constant, which is the main factor that degrades the quality of the regulation process. The larger the Tw, the greater the deviation of the speed, the greater the number of fluctuations, the longer the adjustment time, and even beyond the stability zone.

Generator and load transfer function is[6]:

$$
\mathrm{G}_{\mathrm{g}}(\mathrm{s}) \frac{1}{\left(\mathrm{~T}_{\mathrm{a}}+\mathrm{T}_{\mathrm{b}}\right) \mathrm{s}+\mathrm{e}_{\mathrm{n}}}
$$

Where $\mathrm{Ta}$ is the moment of inertia of the unit. $\mathrm{Tb}$ is the inertial magnitude of the load. According to domestic and international experience, Tb is generally taken to be 0.24 0.3 times Ta. En is the unit's self-adjustment coefficient, the larger the en, the more conducive to stabilizing and improving the quality of dynamic regulation.

\section{Fuzzy PID Controller}

The input to the fuzzy controller is e and ec, and the outputs are $\mathrm{kp}, \mathrm{ki}$, and $\mathrm{kd}$. It is a two-input, three-output structure. The real-time $\mathrm{kp}$, ki, and kd parameters are obtained by the fuzzy controller according to the deviation between the expected value of different working conditions and the actual output value of the system and the rate of change of deviation ec, and the controlled object is controlled by the PID controller.

The fuzzy domain of e is $[-6,6]$, the fuzzy domain of ec is $[-6,6]$, the fuzzy domain of $\mathrm{kp}$ is 
[0,3.5], and the fuzzy domain of ki is [0.01,0.8], The fuzzy domain of kd is [0,3.3], the membership function of e and ec is set to Gaussian function, the membership function of $\mathrm{kp}, \mathrm{ki}$, $\mathrm{kd}$ is set to triangle function, and the fuzzy rules are NB, NM, NS, ZO, PS, PM, and PB consist of 49 rules. Use the Fuzzy toolbox in Matlab to set the structure and parameters of the fuzzy PID controller. The fuzzy PID controller is shown in Figure 2.

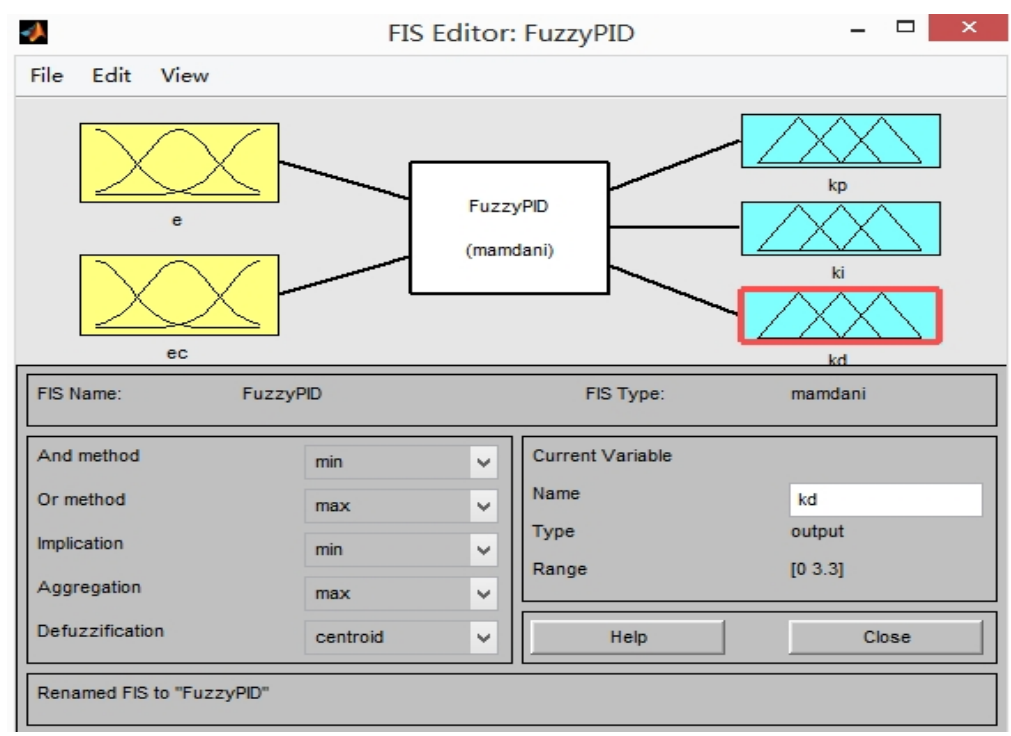

Figure 2 fuzzy PID controller

In the design of fuzzy control rules, kp mainly affects the response speed of the system and the magnitude of overshoot. The larger the $\mathrm{kp}$, the faster the system response speed, but the overshoot will increase. Therefore, in the design of $\mathrm{kp}$, it must be adopted first. A larger kp value increases the response speed of the system, and then uses a smaller kp value to reduce the overshoot; ki mainly reduces the steady-state error of the system, so in the design of ki, the smaller ki is used first. Values to prevent the system's integral saturation, and then use a larger value of ki to reduce the system's steady-state error; $\mathrm{kd}$ is mainly for controlled objects with large inertia links, in the design of $\mathrm{kd}$, first select the larger $\mathrm{kd}$ To reduce the overshoot of the system, use a smaller kd to reduce its braking effect on the controlled process. Therefore, the fuzzy control rules for $\mathrm{kp}$, $\mathrm{ki}$, and $\mathrm{kd}$ are shown in Table 1.

Table 1 Table of fuzzy control rules for $\mathrm{kp}, \mathrm{ki}$, and $\mathrm{kd}$

\begin{tabular}{|c|c|c|c|c|c|c|c|}
\hline e/ec & NB & NM & NS & ZO & PS & PM & PB \\
\hline NB & NS/NS/PS & ZO/NS/ZO & PS/PS/NS & PM/PB/NB & PS/PS/NS & ZO/NS/PS & ZO/NS/ZO \\
\hline NM & NM/NS/PS & NS/ZO/ZO & ZO/PM/NM & PM/PM/NM & PS/PM/NS & ZO/ZO/ZO & ZO/NM/ZO \\
\hline NS & ZO/ZO/ZO & NS/ZO/ZO & PS/PS/NS & PB/PB/NM & PS/PS/NS & ZO/ZO/ZO & ZO/ZO/ZO \\
\hline ZO & $\mathrm{PM/PS/ZO}$ & ZO/ZO/ZO & PS/ZO/NS & PM/PM/NS & PS/ZO/NS & ZO/ZO/ZO & PM/PS/ZO \\
\hline $\mathrm{PS}$ & ZO/ZO/ZO & ZO/ZO/ZO & PS/PS/NS & PB/PB/NM & PS/PS/NS & NS/ZO/ZO & ZO/ZO/ZO \\
\hline $\mathrm{PM}$ & ZO/NM/ZO & ZO/ZO/ZO & PS/PM/NS & PM/PM/NM & ZO/PM/NM & NS/ZO/ZO & NM/NS/PS \\
\hline $\mathrm{PB}$ & ZO/NS/PS & ZO/NS/PS & PS/PS/NS & PM/PB/NB & PS/PS/NS & ZO/NS/ZO & NS/NS/PS \\
\hline
\end{tabular}

\section{Simulation analysis}

\section{Simulation model}

The flow inertia time constant $\mathrm{Ta}=1.5 \mathrm{~s}$ in the building hydroelectric system, the main servomotor time constant $\mathrm{Ty}=0.2 \mathrm{~s}$, ey $=0.75$, eh $=1.4$, eqy $=0.8, \mathrm{eqh}=0.5, \mathrm{Ta}=6.4 \mathrm{~s}, \mathrm{~Tb}=1.6 \mathrm{~s}$, en $=1.5$. The above parameters are substituted into the transfer function of the turbine and combined with the fuzzy PID 
controller to form the simulation model of the turbine speed control system[7]. The Simulink simulation diagram is shown in Figure 3.

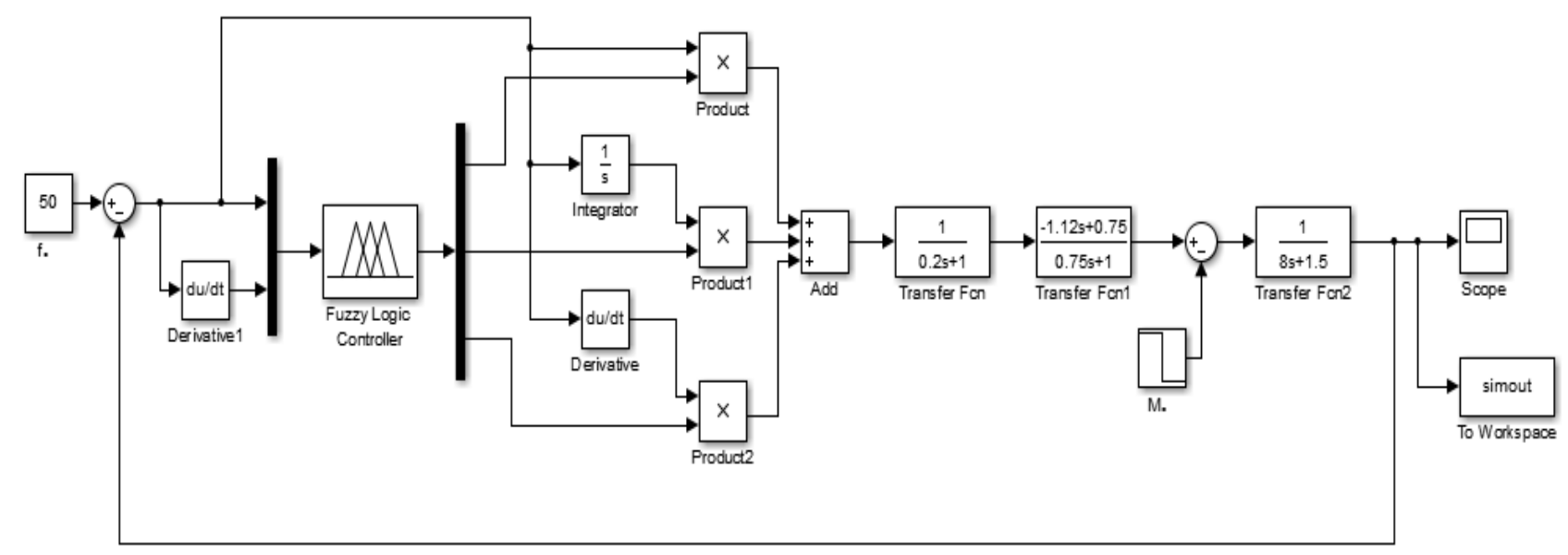

Figure 3 Turbine speed regulation and power generation system simulation model

\section{Simulation results}

Take the simulation end time as 50s, and add a step signal to simulate the frequency change process of the turbine load rejection at the simulation time of $25 \mathrm{~s}$. The simulation results of the turbine start and load rejection are shown in Figure 4.

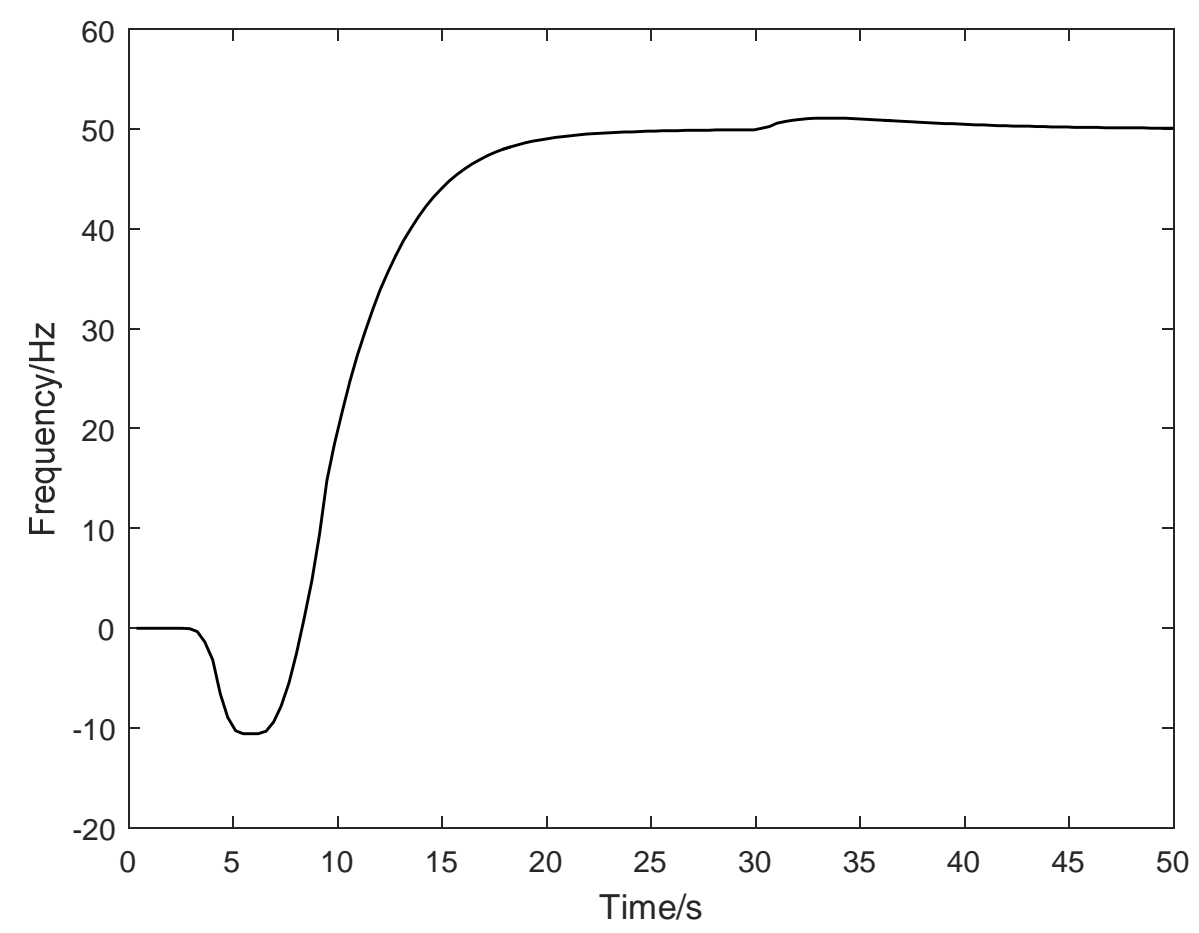

Figure 4 Turbine startup and load rejection simulation

As can be seen from Figure 4, the first $25 \mathrm{~s}$ is the start-up process of the turbine. Because of the presence of the water hammer effect, the frequency of the system will decrease first and then increase. The frequency of the system can be stabilized at $50 \mathrm{~Hz}$ at 15 seconds, and the system responds quickly and no overshoot occurs. The reliability of fuzzy PID control is explained. When the load rejection simulation of the system is performed at $25 \mathrm{~s}$, the frequency of the turbine will rise first and then decrease. Then the system frequency will be stabilized at $50 \mathrm{~Hz}$ within $18 \mathrm{~s}$.

Therefore, the use of fuzzy PID control for turbine speed control can effectively stabilize the 
frequency of the system is $50 \pm 0.2 \mathrm{~Hz}$, and the response is fast, no overshoot will occur, laying the foundation for the future of the building's hydroelectric power system and the grid.

\section{Conclusions}

The resource utilization of building water energy is a project that all countries in the world have attached great importance to. In this paper, the fuzzy PID controller is designed as the governor of the hydraulic turbine, combined with the parameters of the building hydroelectric power system, the system is modeled and simulated using Matlab, and the power generator startup process and the load rejection process are simulated and analyzed. The experimental results show that the fuzzy PID controller can be used as the governor of the building hydropower system. The response curve of the system has good control effect in terms of adjustment time, overshoot or steady state error. The output frequency of the stable system is $50 \pm 0.2 \mathrm{~Hz}$, which has reached the frequency of grid-connected conditions, laying the foundation for the future grid-connected construction of the building hydropower system.

\section{Acknowledgement}

This work was financially supported by National Science and Technology Support Program(201 5BA107b04) and Fujian Province Science and Technology Plan Project (2014H0031), People's Republic of China.

\section{References}

[1] Frede Blaabjerg, Ke Ma. Future on Power Electronics for Wind Turbine Systems[J]. IEEE Journal of Emerging and Selected Topics in Power Electronics, 2013, 1(3):139-152. .

[2] Wang Qian, Xu Hongcheng, Lei Chun, et al. Energy saving rainwater power generation lighting system[J]. Journal of Beijing Electric Power College: Natural Science, 2011， 28.

[3] Liu Jianjiao. Simulation Study of Turbine Regulation System Based on Fuzzy PID[D]. Northwest A\&F University, 2012.

[4] Ma Zhenyue. Dynamics of hydro-generator units [M]. Dalian University of Technology Press, 2003.

[5] Wei Shouping. Modern Turbine Regulation Technology [M]. Huazhong University of Science and Technology Press, 2002.

[6] Li Hua, Shi Keqin, Fan Yue, et al. Model Structure Analysis of Water Turbine Governor for Power System Stability Calculation[J]. Power System Technology, 2007, 31(5):25-28.

[7] Wang Peipei. Research on Turbine Regulation System Based on Fuzzy Theory[D]. Hubei University of Technology, 2011. 